\title{
Physician allocation system in Quebec inhibits recruitment
}

$\mathrm{A}$ ctizens' committee in southern Quebec is calling for a change to the way doctors are allocated within the province.

"The doctor shortage in BromeMissisquoi" - a county in the Eastern Townships, south of Montréal — "is one of the worst in the province," says Dr. Robert Pincott, a retired physician. One in 5 residents in Brome-Missisquoi lacks a family doctor.

Pincott says the committee would like to recruit 5 family doctors and 6 specialists for 2009 , but the government's system of allocation prevents that. The committee hopes to pressure the government to allocate more doctors to the area.

"We expect the number of people without a family doctor to go from 12000 to 15000 in the next few years due to retirements," says Pincott. According to the Brome-Missisquoi Health Network, as many as 7 doctors will retire by 2010 , and 18 by 2020 . These numbers do not include doctors who decide to stop practising in the region.

If the current allocation system is left unfixed, Pincott fears that retiring doctors won't be replaced and remaining doctors will be overworked.

In Quebec, 1 in 8 residents are looking for a family doctor. The national ratio is 1 in 6 .

Pincott acknowledges that the problem stems in part from the provincial and national doctor shortage, but he says the provincial Ministère de Santé et les Services sociaux (Ministry of Health and Social Services) and the regional agencies for health and social services (known collectively as the Agence) share some of the blame because of the way positions are allocated.

Each year, the ministry calculates the number of family doctors who will begin practising in Quebec. They may be recent graduates, or family doctors who have migrated from another province or country. The ministry estimates 220 newly billing family doctors will be added to the ranks this year.

In 2004, the ministry and the Quebec Federation of General Practitioners set a goal of having one family doctor for every 1500 residents.
After weighing supply against demand, the ministry sets an annual recruitment target for family doctors for each of the province's 18 administrative regions.

"We want each region to benefit, but there are choices that have to be made," says Daniel Poirier, director of medical manpower for the ministry of health and social services.

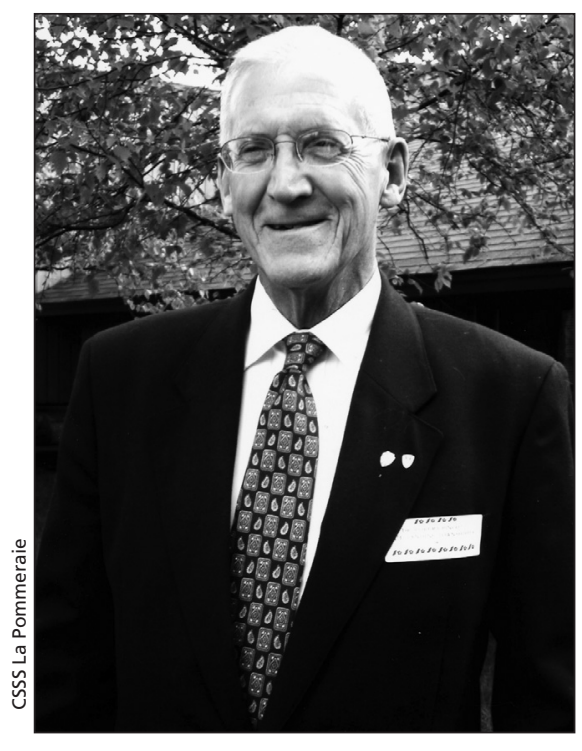

Quebec's allocation system must be overhauled, says Dr. Robert Pincott.

After receiving these targets, the regional department of general medicine and the Agence identify the needs of hospitals and centres de santé et de services sociaux (CSSS, or health and social services centres).

Brome-Missisquoi, for example, is served by the CSSS La Pommeriae, 1 of 11 CSSS in the Montérégie region. For 2009, Montérégie will be allowed to recruit 24 newly billing family doctors and 21 family doctors who have practised elsewhere in the province for more than a year. The CSSS La Pommeraie has been granted 2 of the posts for newly billing family doctors and 3 of the posts for established doctors for 2009.

Although this is a boost over the allocation of new doctors made in 2006 (1), 2007 (0) and 2008 (1), it will not meet the goals of the BromeMissisquoi Health Network. Their goal is to recruit 6 newly practising family doctors for 2009 - and another 5 for 2010 - in addition to 5 specialists.

The Agence doesn't distinguish between regional and urban settings or the practice model, says Pincott. Brome-Missisquoi is a rambling rural area dotted with vineyards, sugar shacks and ski hills. It contains the towns of Knowlton, Cowansville and Sutton, and its 60000 permanent residents are distributed over $2289 \mathrm{~km}^{2}$ where a journey by ambulance to Brome-Missisquoi-Perkins Hospital can take as long as 30 minutes.

This will change in 2010, when distance and population density will be included in ministry calculations. "The work has been done to the satisfaction of all the partners, but the details and its impact will be announced in the coming months," says Poirier.

The government estimates it lacks 760 full-time family doctors, and according to the National Physician Survey, more than 1300 doctors — including more than 500 family physicians are expected to stop practising in the province by 2010 . To fill this gap, the government has increased enrolment in the province's medical schools, from 406 in 1998 to 796 in 2009.

Critics point out that not all Quebectrained doctors will stay in the province. In addition, medical students are eschewing family medicine for specializations such as urology and surgery, which pay more and may be viewed as more esteemed. Of 346 positions in family medicine made available in the province in 2008, only 300 were filled, says Dr. Louis Godin, president of the Quebec Federation of General Practitioners. "Quebec must have a province-wide policy on family medicine. Action is urgently required."

Students are frequently taught by specialists and need earlier exposure to family medicine, says Dr. Serge Dulude, the federation's director of planning and regionalization. He adds that family doctors face an income gap and pressure to take on new patients can force them out of the province. Hannah Hoag, Montréal, Que.

DOI:10.1503/cmaj.081789 